Terr. Atmos. Ocean. Sci., Vol. 18, No. 3, 459-474, August 2007

\title{
Search for Man-Made Cirrus Contrails over Southeast Asia
}

\author{
Christos S. Zerefos ${ }^{1,}$ 2, 3, * , Kostas Eleftheratos ${ }^{1,2}$, Prodromos Zanis ${ }^{4}$, \\ Dimitris S. Balis ${ }^{5}$, and George Tselioudis ${ }^{6}$
}

(Manuscript received 30 March 2006, in final form 13 September 2006)

\begin{abstract}
In this study we examine the effect of natural perturbations on cirrus cloud cover in the tropics and we look for possible signal of cirrus contrails in tropical air traffic regions focussing on Southeast Asia, a region that has received much less attention than the well investigated North Atlantic and North American air traffic corridors. The analysis is based on the latest version of the ISCCP D2 cirrus cloud dataset and covers the period 1984 2000. Four parameters were examined for their relation with cirrus cloud trends: deep convective clouds from ISCCP, vertical velocities, relative humidity and air temperature at $200 \mathrm{mb}$ from ECMWF/ERA40. The results show that there is a strong correlation between cirrus clouds and dynamical parameters (deep convective clouds, vertical velocities) over Southeast Asia, explaining a significant part of the tropical cirrus cloud variability. After removing seasonality, the ENSO signal becomes dominant on cirrus, on deep convective clouds and on vertical velocities over regions of the western and the eastern tropical Pacific Ocean. Over Southeast Asia, the average decrease in cirrus during the strong 1997/98 EI Nino event was about $6 \%$ cloud cover or $\sim 25 \%$ of the regional mean. In order to search for possible signal of cirrus contrails over S. E. Asia, we calculated trends in cirrus
\end{abstract}

${ }^{1}$ Laboratory of Climatology and Atmospheric Environment, University of Athens, Athens, Greece

${ }^{2}$ Foundation for Biomedical Research, Academy of Athens, Athens, Greece

${ }^{3}$ National Observatory of Athens, Athens, Greece

${ }^{4}$ Research Centre for Atmospheric Physics and Climatology, Academy of Athens, Athens, Greece

${ }^{5}$ Laboratory of Atmospheric Physics, University of Thessaloniki, Greece

${ }^{6}$ Goddard Institute of Space Studies, NASA, USA

* Corresponding author address: Prof. Christos S. Zerefos, Laboratory of Climatology and Atmospheric Environment, University of Athens, Athens, Greece; E-mail: zerefos@geol.uoa.gr doi: 10.3319/TAO.2007.18.3.459(EA) 
coverage over tropical regions with high air traffic after removing the ENSO effect. The results show that there is a small positive trend in cirrus clouds over the S. E. Asia air corridors during winter $(+0.1 \%$ cover/decade), which is not statistically significant and is related to small positive trends in deep convective clouds. In summer, cirrus clouds are anti-correlated with deep convective clouds over this region and the trends are opposite. The negative trends in cirrus clouds, which are observed in the summer $(-4.5 \%$ cover/ decade), are related to trends in dynamical and thermo-dynamical parameters. It is shown that cirrus clouds are statistically significant correlated with vertical velocities and air temperature at $200 \mathrm{mb}$ (correlations of -0.7 and $\mathbf{- 0 . 6}$, respectively), explaining the highest part of the long-term variability of cirrus clouds over S. E. Asia. Over the Caribbean air corridors, on the other hand, there are significant increases in cirrus cloudiness by about $2.5 \%$ per decade in winter $(99 \%$ confidence level) and $2.7 \%$ cover/ decade in the summer ( $95 \%$ confidence level), part of which is also related to trends in dynamical and thermo-dynamical parameters. According to our findings, it is difficult to detect possible effects of regional persistent contrails on cirrus cloud trends over the S. E. Asia air traffic corridors. This is because in winter there are not statistically significant trends in cirrus clouds and in summer trends in dynamics and thermo-dynamics mask this issue. Taking also into account that flight frequencies and fuel consumption are moderate over the tropical air traffic corridors, it makes it even more difficult to detect and quantify any possible anthropogenic effects.

(Key words: Cirrus clouds, Cirrus contrails, Trends, Southeast Asia)

\section{INTRODUCTION}

Recent studies on the effects of aviation on cirrus clouds (Zerefos et al. 2003; Minnis et al. 2004; Stordal et al. 2005; Stubenrauch and Schumann 2005) have shown evidence of increasing trends in cirrus/high cloud coverage over congested air traffic locations in possible association with aviation activities.

Zerefos et al. (2003) after removing correlations related to natural perturbations (such as ENSO, QBO, NAO, and tropopause temperatures) found a statistically significant positive correlation $(+0.7)$ between decadal changes in cirrus cloud cover and aviation fuel consumption along the latitude belt centred at the North Atlantic air traffic corridor, providing an independent test of possible impact of aviation on contrail cirrus formation.

Minnis et al. (2004) found that seasonal cirrus changes over the United States were generally consistent with the annual cycle of contrail coverage and frequency lending additional evidence to the role of contrails in the observed trend. It was concluded that the U.S. cirrus trends were most likely due to air traffic.

In Europe, Stordal et al. (2005) found indications of a trend of about $1-2 \%$ cloud cover per decade due to aircraft, in reasonable agreement with previous studies. Even though they 
found moderate correlations between trends in cirrus cloud cover and aircraft density data, as many other factors could have also contributed to changes in cirrus, they still regarded their results to be indicative of an impact of aircraft on cirrus amount.

Stubenrauch and Schumann (2005) provided another link of cirrus increase to air traffic by comparing cirrus trends for meteorological situations favourable for contrail formation to those in general and those favourable for cirrus, based on analysis of TOVS Path-B satellite data of effective high cloud amount and relative humidity over Europe and the North Atlantic flight corridor. In conclusion, they found a weak but significant decadal increase of cirrus in regions where air traffic is very high for situations in which the air is cold and humid enough to let contrails form.

Radiative forcing from aviation induced cirrus clouds might be as large as the present estimate of the total radiative forcing (without cirrus). However, the present knowledge on these anthropogenic-induced cirrus clouds is at present poor to provide reliable estimates on the associated radiative forcing of the atmosphere (Sausen et al. 2005). Over Europe, the aircraft induced cirrus cover is about ten times larger than that of linear contrails in the same region and the radiative forcing from the additional cirrus may be more than 10 times higher than that of linear contrails and aviation induced $\mathrm{CO}_{2}$ increases (Mannstein and Schumann 2005).

In this study we examine the effect of natural perturbations on cirrus cloud cover in the tropics and we look for possible signal of cirrus contrails in tropical air traffic regions focussing on S. E. Asia, a region that has received much less attention than the well investigated North Atlantic and North American air traffic corridors. The ultimate goal of the study is to stimulate more in depth scientific assessments in the future focusing on the S. E. Asia corridor as far as the impact of air traffic on cirrus cloud positive trends is concerned.

\section{DATASETS AND METHODOLOGY}

\subsection{ISCCP Cloud Data}

Mean monthly cirrus cloud data from the International Satellite Cloud Climatology Project (ISCCP)(Rossow and Schiffer 1999) were used to calculate long-term changes in cirrus cloud cover from 1984 to 2000 . The data are based on observations from the suite of operational geostationary and polar orbiting satellites. Visible radiances are used to retrieve the optical thickness of clouds and infrared radiances to retrieve cloud top temperature and pressure. The D2 dataset used in this study has a spatial resolution of $280 \mathrm{~km}\left(2.5^{\circ}\right.$ at the equator) and provides monthly averages of cloud properties of fifteen different cloud types. The cloud types are derived based on radiometric definitions that rely on cloud optical thickness and cloud top pressure. Cirrus clouds are defined as those with optical thickness less than 3.6 and cloud top pressure less than $440 \mathrm{mb}$. Deep convective clouds are defined as those with optical thickness greater than 23 and cloud top pressure less than $440 \mathrm{mb}$.

In the latest (D-series) version of the ISCCP dataset, changes in the retrieval thresholds and the inclusion of an ice microphysics model for retrieval of optical thicknesses and top temperatures of cold clouds, have improved the agreement of cirrus cloud amounts with both surface observations (Rossow and Schiffer 1999) and High-Resolution Infrared Sounder (HIRS) 
data (Stubenrauch et al. 1999). An underestimate of ISCCP cirrus clouds amounts ( 5\% at middle latitudes and $\sim 15 \%$ in the tropical warm pool) compared to HIRS results is caused by missed detection of very thin clouds (Rossow and Schiffer 1999; Stubenrauch et al. 1999). Liao et al. (1995) had shown that the frequency of high-level clouds from SAGE II is about 3 times higher than the cloud amount from ISCCP with little seasonal variation. Despite this large systematic difference it was noted that the correlation between the zonal mean curves is high, 0.88 (99.99\% confidence level) for July and 0.82 (99.99\% confidence level) for January, which strengthens our results.

\subsection{ECMWF Reanalysis Data}

Vertical velocities, relative humidity and air temperature at $200 \mathrm{mb}$ were analysed from the ECMWF/ERA40 Reanalysis datasets ${ }^{1}$ for the period 1984 - 2000. ECMWF provides mean monthly gridded values of various atmospheric and surface parameters on $2.5^{\circ} \times 2.5^{\circ}$ grid boxes on a global scale $\left(90^{\circ} \mathrm{N}-90^{\circ} \mathrm{S}, 0^{\circ} \mathrm{E}-357.5^{\circ} \mathrm{E}\right)$. We made use of the monthly daily means which are monthly means from base times 0000, 0600, 1200, and 1800 UTC. The vertical velocity is the vertical displacement in a pressure unit over time (in $\mathrm{Pa} \mathrm{s}^{-1}$ ) and was used, in addition to deep convective clouds, as a tracer of dynamics (convective activity) in the upper troposphere. As a tracer of thermo-dynamical variability over the studied areas we analysed trends in relative humidity and air temperature at $200 \mathrm{mb}$. Potential contrail formation is strongest at high altitudes $(150-200 \mathrm{mb})$ over the tropics, where it is very cold and where sufficient moisture is available because of tropical convection (Sausen et al. 1998).

\subsection{Methodology}

To answer the question of whether observed trends in cirrus clouds over S. E. Asia are associated with man-made cirrus contrails or are caused by natural sources, we have analysed meteorological parameters in the region to evaluate whether observed changes in cirrus clouds are related to dynamical and thermo-dynamical variability. The analysis is also performed for the Caribbean Sea for comparison purposes with a region that experiences similar flight frequencies and fuel consumption.

In a first step, we determine the correlation between cirrus clouds, deep convective clouds and vertical velocities at each individual grid box in order to identify regions in the tropics in which cirrus cloud changes could be related to dynamical variability. The correlations of these variables with cirrus clouds are shown on correlation maps, which were based on the correlation coefficient of the time series of the monthly means of any of these variables from January 1984 to December 2000 (180 data points, excluding years 1991/92) with the respective time series of cirrus at each grid point.

Next, we examine the effects of transient El Nino phenomena on cloudiness, which could also influence the variance of tropical cirrus clouds. After removing from the datasets seasonality and correlations related to El Nino/Southern Oscillation (ENSO), we analyse seasonal

\footnotetext{
${ }^{1}$ http://data.ecmwf.int/data/d/era40 moda/
} 
trends in cirrus clouds over Southeast Asia and the Caribbean Sea and investigate whether the observed trends in cirrus reflect trends in dynamics and thermo-dynamics. Having determined dynamical and thermo-dynamical variability on cirrus cloud trends over the tropical air traffic corridors, we discuss the potential impact of cirrus contrails on tropical cirrus clouds.

To overcome the effect of seasonal variations in the estimated trends, all trends were calculated after removing variations related to the seasonal cycle of the data. Cirrus cloud data were deseasonalized by subtracting the long-term monthly mean (1984 - 2000) pertaining to the same calendar month. All trends have been evaluated as to their statistical significance by applying the t-test of each trend against the null hypothesis of no-trend for the appropriate number of degrees of freedom. Because of the contamination of the ISCCP satellite signal by the Mt. Pinatubo eruption due to the additional visible reflection by volcanic aerosols hanging around in the stratosphere (Rossow and Schiffer 1999), cloud data taken between 1991 and 1992 were not used in our analysis in order to minimize the impact of the volcanic eruption on the satellite retrievals.

\section{RESULTS AND DISCUSSION}

Figure 1 shows the annual mean cirrus cloud amount (in \% cover) for the period 1984 2000 over the globe. As can be seen from Fig. 1, regions within the Inter-Tropical Convergence Zone (ITCZ) are regions with the highest cirrus cloud amounts in all seasons. The mean annual cirrus cloud cover in the tropics, according to ISCCP, exceeds 18\%. The highest amounts are observed over Micronesia (30 - 35\%) and over central Africa (25 - 30\%). Extensive cirrusfree ocean regions are also observed in the tropics, which correspond to the persistent highpressure systems over these regions. These features are consistent to previous studies (Wang et al. 1996). Over Southeast Asia, the annual mean cirrus coverage amounts to 24\%.

The geographical distribution of cirrus cloud cover reflects the characteristics of cloud activities with deep convection in the tropics. Cirrus cloud cover is strongly correlated to deep convective cloud cover and to vertical air motions in the tropics (Figs. 2 and 3, respectively). These correlations determine more than $50 \%$ of the variance in cirrus coverage at some locations and can be attributed mostly to the seasonal cycle. Over S. E. Asia, the correlation between the monthly mean cirrus cloud cover and monthly mean deep convective cloud cover from January 1984 to December 2000 is about +0.7 (statistically significant at the $99 \%$ confidence level). The respective correlation with the vertical velocities at $200 \mathrm{mb}$ is also statistically significant (correlation of $-0.8,99 \%$ confidence level).

After removing seasonality from cirrus coverage, ENSO opposing signals become dominant over regions of the western and the eastern tropical Pacific Ocean, determining a significant part of the cirrus inter-annual natural variability (Wang et al. 2003). Relative to normal conditions, the strong El Nino episode in 1997/98 caused significant increases in cirrus cloudiness over the tropical Pacific Ocean by about $10-15 \%$ and comparable decreases over Micronesia (Fig. 4). These changes are related to proportional changes in deep convective cloud amount and in vertical air motions as seen in Figs. 5 and 6, respectively. Over Southeast Asia, the average decrease in cirrus during the strong 1997/98 El Nino event was about 6\% cloud cover or $\sim 25 \%$ of the regional mean. 


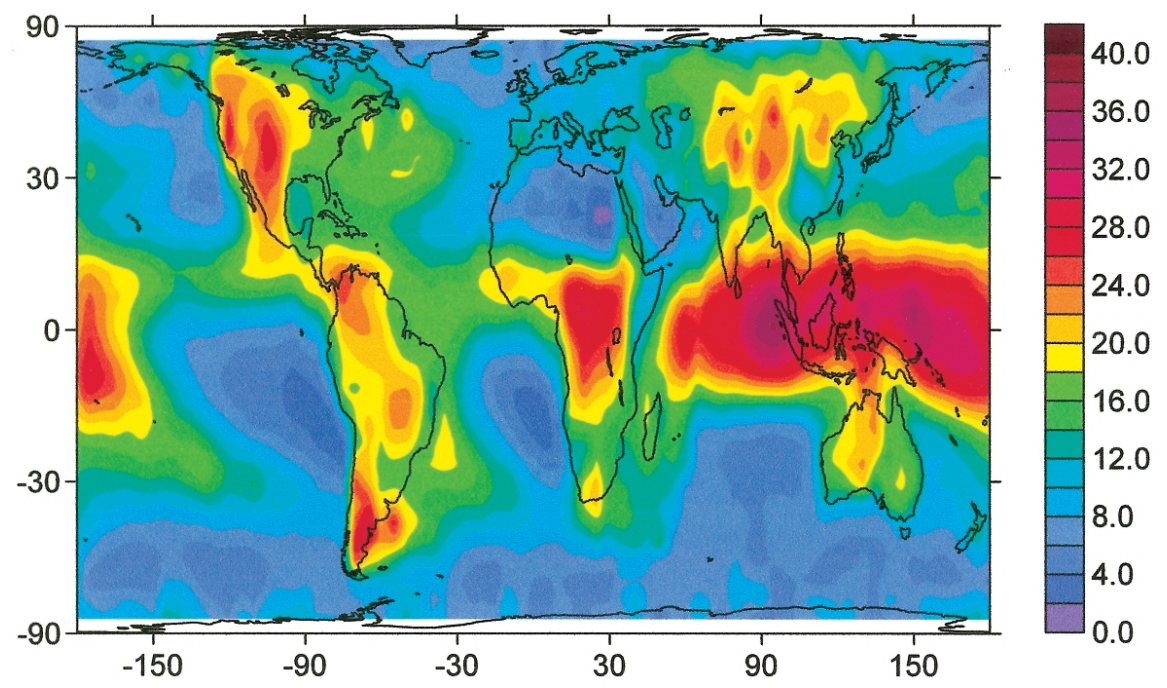

Fig. 1. Latitude-longitude map of annual mean cirrus cloud amount (in \% cover) derived from the ISCCP satellite cirrus cloud dataset for the period 1984 - 2000. The latitudinal axis is the sin function of latitude.

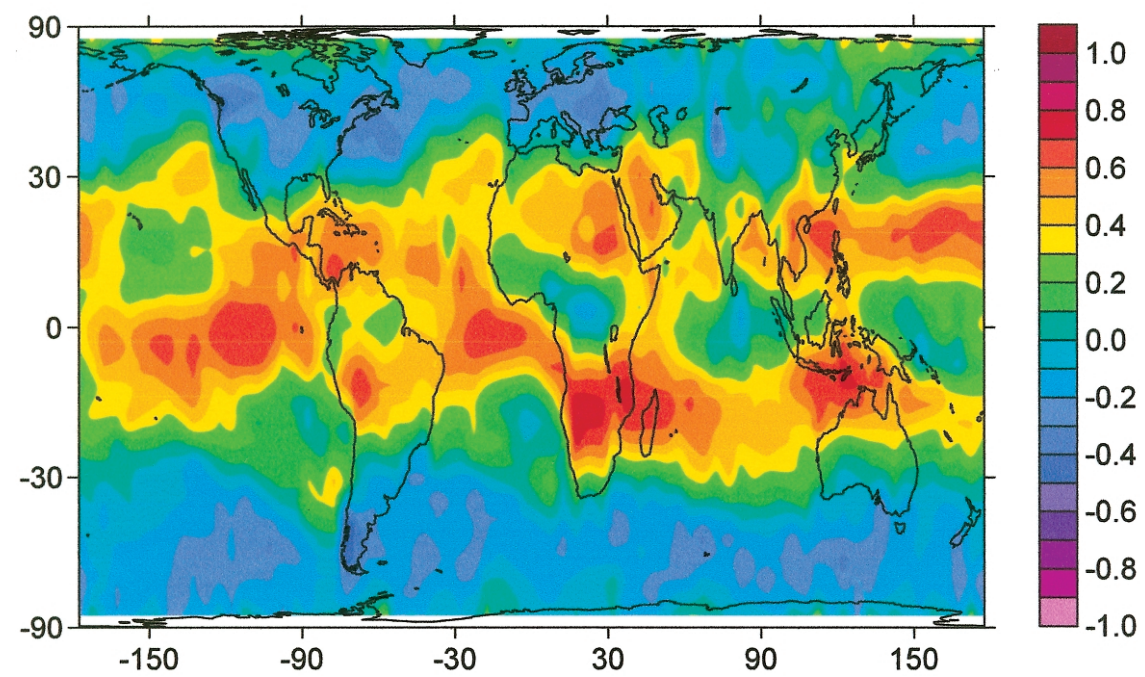

Fig. 2. Latitude-longitude map of correlation coefficients between monthly mean cirrus cloud cover and monthly mean deep convective cloud cover from January 1984 to December 2000. The highest correlations (up to +0.7 ) are found in the tropics. The latitudinal axis is the sin function of latitude. 


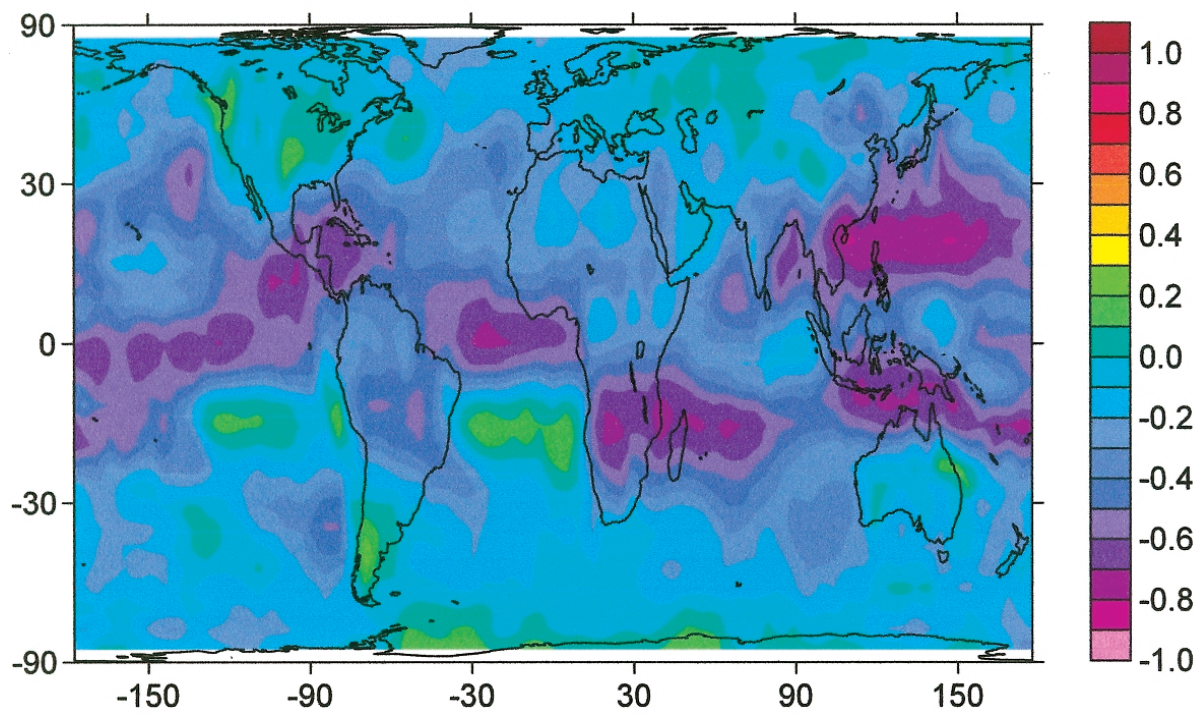

Fig. 3. Latitude-longitude map of correlation coefficients between monthly mean cirrus cloud cover and monthly mean vertical velocities at $200 \mathrm{mb}$ from January 1984 to December 2000. The highest correlations (up to -0.8) are found in the tropics. The latitudinal axis is the sin function of latitude.

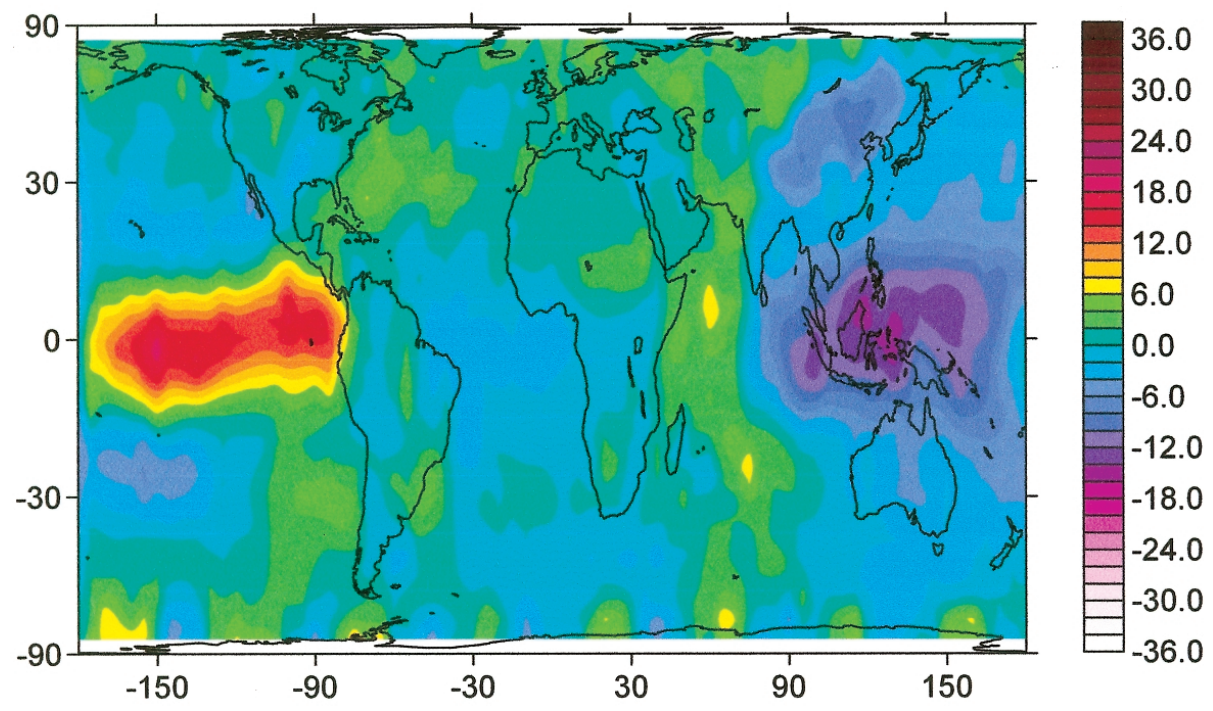

Fig. 4. Latitude-longitude map of deseasonalized cirrus cloud amount (in \% cover) in 1997/98 ENSO years. The latitudinal axis is the sin function of latitude. 


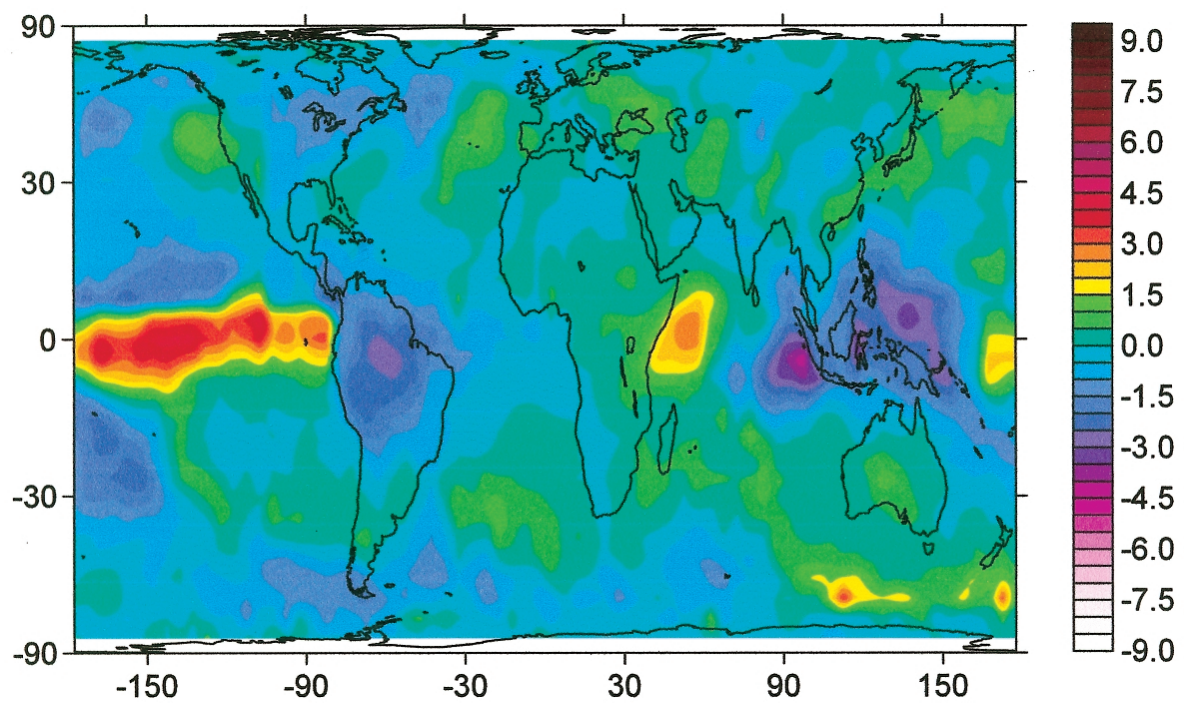

Fig. 5. Latitude-longitude map of deseasonalized deep convective cloud amount (in \% cover) in 1997/98 ENSO years. The latitudinal axis is the sin function of latitude.

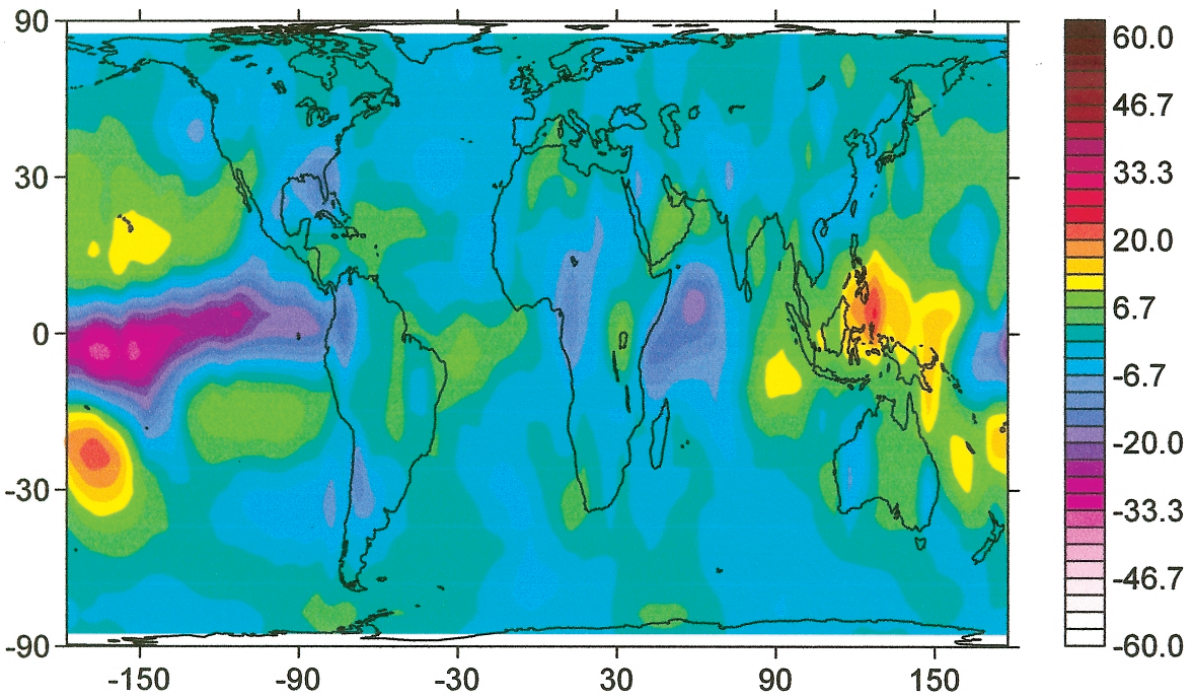

Fig. 6. Latitude-longitude map of deseasonalized vertical velocities at $200 \mathrm{mb}$ (in $\mathrm{mPa} \mathrm{s}^{-1}$ ) in 1997/98 ENSO years. The latitudinal axis is the sin function of latitude. 
Possible signal of cirrus contrails on tropical natural cirrus was investigated by calculating trends in cirrus coverage over the Southeast Asia air corridors $\left(0^{\circ} \mathrm{N}-25^{\circ} \mathrm{N}, 90^{\circ} \mathrm{E}-120^{\circ} \mathrm{E}\right)$ and over the Caribbean air traffic corridors $\left(0^{\circ} \mathrm{N}-25^{\circ} \mathrm{N}, 60^{\circ} \mathrm{W}-90^{\circ} \mathrm{W}\right)$. A general climatology of cirrus clouds over these regions is provided in Table 1. Table 1 also shows the wintertime and summertime averages of deep convective clouds, vertical velocities, relative humidity and air temperature at $200 \mathrm{mb}$. As can be seen from Table 1, the averaged cirrus amount over S. E. Asia is $\sim 12 \%$ higher in the summer when compared to the winter, as a result of the influence of the summertime Monsoon circulation system in the tropics. The corresponding difference between the summertime and wintertime averages of deep convective clouds amounts to $\sim 6 \%$. The dominant winds, which are downward in the wintertime, turn into upward in the summertime and are being enhanced. Relative humidity is always higher in the summertime when compared to the wintertime and air temperatures at $200 \mathrm{mb}$ are always low (about $-50^{\circ} \mathrm{C}$ ).

Potential contrail formation is strongest at high altitudes $(150-200 \mathrm{mb})$ over the tropics, where it is very cold and where sufficient moisture is available because of tropical convection (Sausen et al. 1998). On the other hand at the same altitude range (around $200 \mathrm{mb}$ ) there is enough air traffic to produce contrails and hence it is possible that our cirrus amounts may also include persistent contrails and that our cirrus trends may be attributed not only to trends in natural cirrus, but also to trends in cirrus contrails ${ }^{2}$.

Table 1. Seasonal averages of cirrus clouds (in \% cover), deep convective clouds (in $\%$ cover), vertical velocities at $200 \mathrm{mb}$ (in $\mathrm{mPa} \mathrm{s}^{-1}$ ), relative humidity at $200 \mathrm{mb}$ (in \%) and air temperature at $200 \mathrm{mb}$ (in ${ }^{\circ} \mathrm{C}$ ) over Southeast Asia $\left(0^{\circ} \mathrm{N}-25^{\circ} \mathrm{N}, 90^{\circ} \mathrm{E}-120^{\circ} \mathrm{E}\right)$ and the Caribbean Sea $\left(0^{\circ} \mathrm{N}-25^{\circ} \mathrm{N}\right.$, $60^{\circ} \mathrm{W}-90^{\circ} \mathrm{W}$ ) for the period $1984-2000$. The negative (positive) signs in vertical velocities indicate the upward (downward) winds.

\begin{tabular}{ccccc}
\hline Averages & \multicolumn{2}{c}{ Southeast Asia } & \multicolumn{2}{c}{ Caribbean Sea } \\
\hline & Winter (DJFM) & Summer (JJAS) & Winter (DJFM) & Summer (JJAS) \\
\hline Cirrus (in \% cover) & 17.8 & 29.6 & 11.5 & 21.9 \\
Convective (in \% cover) & 2.6 & 8.7 & 1.5 & 4.9 \\
V. Velocities (in mPa/s) & 6.1 & -31.6 & 5.7 & -10.4 \\
R. Humidity (in \%) & 46.9 & 70.7 & 36.6 & 60.5 \\
Temperature (in ${ }^{\circ} \mathrm{C}$ ) & -52.7 & -51.4 & -53.1 & -53.8 \\
\hline
\end{tabular}

\footnotetext{
${ }^{2}$ The proportion of flights in the altitude range around $200 \mathrm{mb}$ in the tropics is about $10 \%$ at $195 \mathrm{mb}$ and about $18 \%$ at $217 \mathrm{mb}$ (Spichtinger, 2004, Fig. 2.1: Distribution of MOZAIC flights on pressure levels). Therefore, at the 200 $\mathrm{mb}$ level there is enough air traffic to warrant this statement.
} 
The time series of cirrus cloudiness from 1984 to 2000 over Southeast Asia and the Caribbean Sea in winter and in summer is presented in Figs. 7 and 8. For comparison, the time series of deep convective clouds is also shown. The results show that there is a small positive trend in cirrus clouds over the S. E. Asia air corridors during winter $(+0.1 \%$ cover/decade), which is not statistically significant and could be related to the small positive trend in deep convective clouds. In summer, cirrus clouds are anti-correlated with deep convective clouds over this region and the trends are opposite. Over the Caribbean air corridors, on the other hand, there are significant increases in cirrus cloudiness by about $2.5 \%$ per decade in winter (99\% confidence level) and $2.7 \%$ cover/decade in the summer (95\% confidence level), which are not related to trends in deep convective clouds. It should be noted that flight frequencies and fuel consumption over the two target tropical areas, Southeast Asia and the Caribbean Sea, are moderate (shown, for example, in Fig. 1 of Zerefos et al. 2003). Thus, if a trend in contrail-cirrus exists, the trend is likely to be small. From the results shown in Figs. 7 and 8, a decadal positive trend in cirrus coverage does exist especially in the area over the Caribbean Sea. The question is whether the trend is indeed associated with contrails or whether it has been caused by natural sources. To answer this question, we have analysed trends in dynamical and thermo-dynamical parameters over Southeast Asia and the Caribbean Sea in winter and in summer and compared them with the observed trends in cirrus clouds (Table 2). Table 3 shows the respective correlation coefficients between the temporal variability of these parameters and the temporal variability of cirrus clouds.

As can be seen from Tables 2 and 3, over Southeast Asia the observed small positive trend in cirrus clouds in winter $(+0.1 \%$ cover/decade $)$ is statistically significant correlated with small positive trends in deep convective clouds (correlation of $+0.8,99 \%$ confidence level). Both of these trends, however, are not statistically significant. Trends in vertical velocities and relative humidity at $200 \mathrm{mb}$ are also not statistically significant (Table 2), neither are their correlations with the cirrus trends (Table 3). Air temperature at $200 \mathrm{mb}$ is also increasing in the region $\left(+0.5^{\circ} \mathrm{C}\right.$ per decade, $95 \%$ confidence level $)$, but this trend is not related to the observed trend in cirrus clouds. Therefore, in the examined period trends in cirrus clouds are likely to be caused by trends in deep convective clouds. In summer, cirrus clouds are anti-correlated with deep convective clouds over this region and the trends are opposite. In summer, there is a statistically significant decreasing trend in cirrus clouds over S. E. Asia ( $-4.5 \%$ cover/decade, $99 \%$ confidence level), which is related to trends in dynamical and thermo-dynamical parameters. As can be seen from Table 3, cirrus cloud cover is strongly correlated with vertical velocities at $200 \mathrm{mb}$ in summer (correlation of -0.7 , statistically significant at the $99 \%$ confidence level), explaining the highest part of the observed long-term variability of cirrus clouds. The upward air motions are decreasing in summer, leading to a decrease in cirrus cloud amounts. To quantify the part of the cirrus cloud trend that is caused by trends in vertical winds, we have derived the respective vertical velocity related cirrus trend by multiplying the regression coefficient between cirrus and vertical velocities with the trend in vertical velocities for the period 1984 - 2000. According to our calculations, the vertical velocity related cirrus trend over S. E. Asia in summer is about $-3.5 \%$ cover per decade, indicating that $\sim 78 \%$ of the observed trend in cirrus is caused by trends in vertical winds. Moreover in summer, air temperature changes at $200 \mathrm{mb}$ are also statistically significant anti-correlated with cirrus cloud changes over S. E. 


\section{Southeast Asia air corridors}

$\left(0^{\circ}-25^{\circ} \mathrm{N}, 9^{\circ}-120^{\circ} \mathrm{E}\right)$

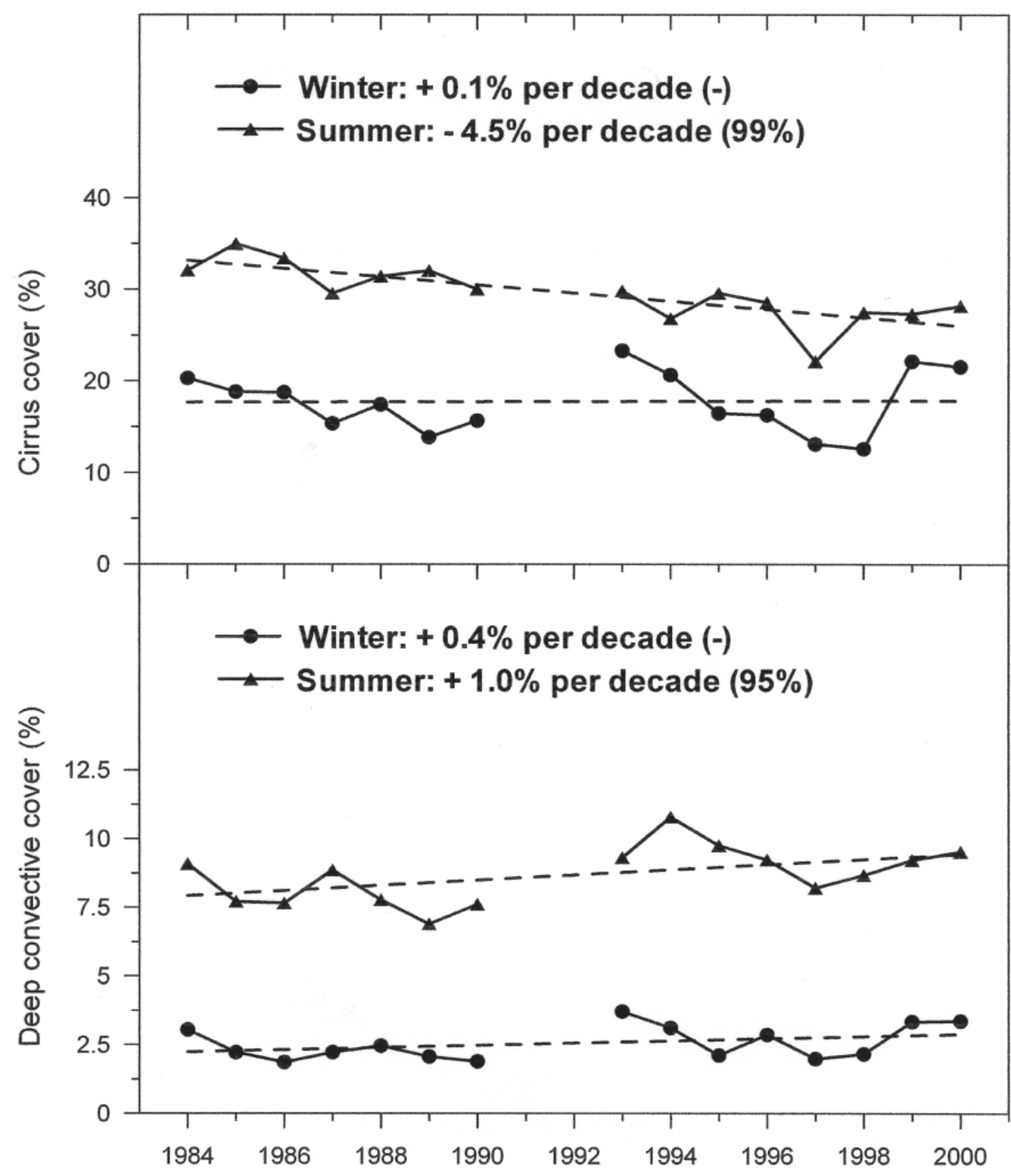

Fig. 7. (Upper panel) Trends in cirrus cloudiness (in \% cover/decade) from 1984 to 2000 in winter (DJFM) and in summer (JJAS) for the Southeast Asia air traffic corridors $\left(0^{\circ} \mathrm{N}-25^{\circ} \mathrm{N}, 90^{\circ} \mathrm{E}-120^{\circ} \mathrm{E}\right)$. (Lower panel) Same as in upper panel but for the deep convective clouds. 


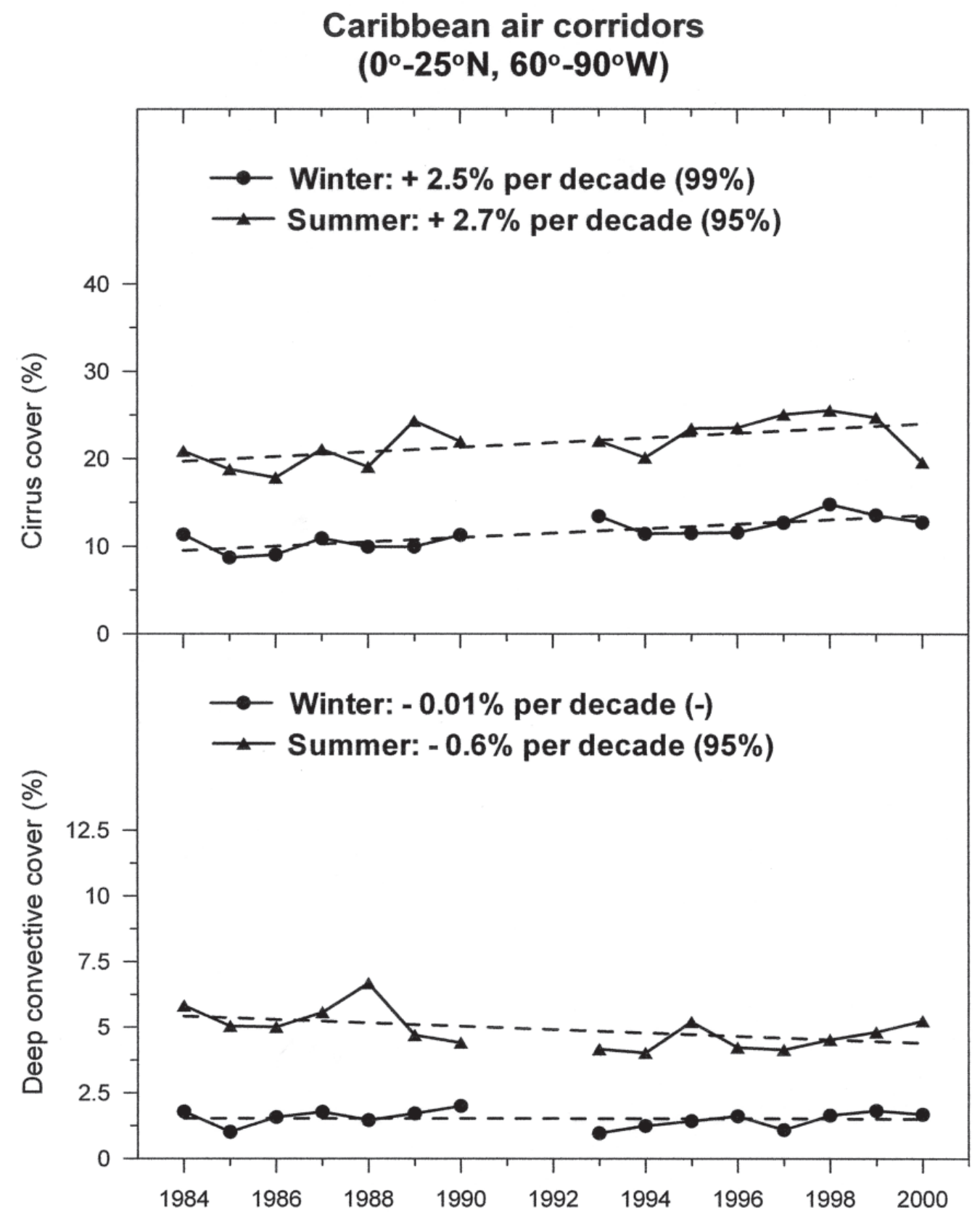

Fig. 8. (Upper panel) Trends in cirrus cloudiness (in \% cover/decade) from 1984 to 2000 in winter (DJFM) and in summer (JJAS) for the Caribbean air traffic corridors $\left(0^{\circ} \mathrm{N}-25^{\circ} \mathrm{N}, 60^{\circ} \mathrm{W}-90^{\circ} \mathrm{W}\right)$. (Lower panel) Same as in upper panel but for the deep convective clouds. 
Table 2. Seasonal trends in cirrus clouds (in \% cover per decade), deep convective clouds (in \% cover per decade), vertical velocities at $200 \mathrm{mb}$ (in $\mathrm{mPa} \mathrm{s}^{-1}$ per decade), relative humidity at $200 \mathrm{mb}$ (in \% per decade) and air temperature at $200 \mathrm{mb}$ (in ${ }^{\circ} \mathrm{C}$ per decade) over Southeast Asia $\left(0^{\circ} \mathrm{N}\right.$ $\left.25^{\circ} \mathrm{N}, 90^{\circ} \mathrm{E}-120^{\circ} \mathrm{E}\right)$ and the Caribbean Sea $\left(0^{\circ} \mathrm{N}-25^{\circ} \mathrm{N}, 60^{\circ} \mathrm{W}-90^{\circ} \mathrm{W}\right)$ from 1984 to 2000. Values in brackets refer to statistical significance of each trend. Dashes in brackets indicate a confidence level less than $95 \%$.

\begin{tabular}{ccccc}
\hline Trends per decade & \multicolumn{2}{c}{ Southeast Asia } & \multicolumn{2}{c}{ Caribbean Sea } \\
\hline & Winter (DJFM) & Summer (JJAS) & Winter (DJFM) & Summer (JJAS) \\
\hline Cirrus (in \% cover) & $+0.1(-)$ & $-4.5(99 \%)$ & $+2.5(99 \%)$ & $+2.7(95 \%)$ \\
Convective (in \% cover) & $+0.4(-)$ & $+1.0(-)$ & $-0.01(-)$ & $-0.6(-)$ \\
V. Velocities (in $\mathrm{mPa} / \mathrm{s})$ & $+0.7(-)$ & $+8.7(99 \%)$ & $-4.8(99 \%)$ & $+0.4(-)$ \\
R. Humidity (in \%) & $-0.7(-)$ & $-0.8(-)$ & $+1.6(-)$ & $+0.3(-)$ \\
Temperature (in $\left.{ }^{\circ} \mathrm{C}\right)$ & $+0.5(95 \%)$ & $+0.5(95 \%)$ & $+0.6(-)$ & $+0.8(99 \%)$ \\
\hline
\end{tabular}

Table 3. Correlation coefficients between the seasonal variability of cirrus clouds and the seasonal variability of deep convective clouds, vertical velocities at $200 \mathrm{mb}$, relative humidity at $200 \mathrm{mb}$ and air temperature at $200 \mathrm{mb}$ over Southeast Asia $\left(0^{\circ} \mathrm{N}-25^{\circ} \mathrm{N}, 90^{\circ} \mathrm{E}-120^{\circ} \mathrm{E}\right)$ and the Caribbean Sea $\left(0^{\circ} \mathrm{N}-25^{\circ} \mathrm{N}, 60^{\circ} \mathrm{W}-90^{\circ} \mathrm{W}\right)$ for the period $1984-2000$. Values in brackets refer to statistical significance of each correlation coefficient. Dashes in brackets indicate a confidence level less than $95 \%$.

\begin{tabular}{ccccc}
\hline \multicolumn{1}{c}{ Correlations } & \multicolumn{2}{c}{ Southeast Asia } & \multicolumn{2}{c}{ Caribbean Sea } \\
\hline & Winter (DJFM) & Summer (JJAS) & Winter (DJFM) & Summer (JJAS) \\
\hline Cirrus - Convective & $+0.8(99 \%)$ & $-0.4(-)$ & $+0.1(-)$ & $-0.5(-)$ \\
Cirrus - V. Velocities & $-0.2(-)$ & $-0.7(99 \%)$ & $-0.8(99 \%)$ & $-0.2(-)$ \\
Cirrus - R. Humidity & $+0.5(-)$ & $+0.1(-)$ & $+0.3(-)$ & $-0.1(-)$ \\
Cirrus - Temperature & $-0.2(-)$ & $-0.6(95 \%)$ & $+0.5(-)$ & $+0.7(99 \%)$ \\
\hline
\end{tabular}

Asia (correlation of $-0.6,95 \%$ confidence level), which can be attributed to the fact that at higher temperatures cirrus clouds form less efficiently and vice-versa. Trends in relative humidity at $200 \mathrm{mb}$ and their correlations with the cirrus trends were not found to be statistically significant in the examined period. 
Over the Caribbean Sea, on the other hand, there is a statistically significant decreasing trend in vertical velocities at $200 \mathrm{mb}$ in winter of $\sim 4.8 \mathrm{mPa} \mathrm{s}^{-1}$ per decade. Since vertical velocities are positive in this region in the wintertime (Table 1), the negative trend that we find suggests a reduction in large-scale downward winds, which could lead to an increase in largescale cirrus clouds. Cirrus trends are indeed positive in the wintertime $(+2.5 \%$ cover/decade) and could be related to the trends in vertical velocities. As can be seen from Table 3, over the Caribbean Sea there is a strong correlation $(-0.8)$ between the variability of cirrus clouds and the variability of vertical velocities in winter, which is statistically significant at the $99 \%$ confidence level. The correlation suggests that $\sim 64 \%$ of the variability of cirrus in winter is explained by variability in vertical velocities at $200 \mathrm{mb}$ and therefore trends in dynamics determine the highest part of the observed cirrus trends. To quantify this part, the respective vertical velocity related cirrus trend is about $+2.0 \%$ cover per decade, indicating that $\sim 80 \%$ of the observed trend in cirrus is caused by trends in vertical winds. Relative humidity at $200 \mathrm{mb}$ is also increasing in the area $(\sim 1.6 \%$ per decade), but this trend is not significantly correlated with the observed trend in cirrus. The remaining part of cirrus cloud variability $(\sim 36 \%)$ is related to other factors, which could also include the possible effects from regional persistent contrails. This part, however, is likely to be small since flight frequencies and fuel consumption in the area are moderate. In summertime, cirrus cloud positive trends in the Caribbean $(+2.7 \%$ cover/decade $)$ are not statistically significant correlated to trends in vertical velocities at $200 \mathrm{mb}$ as it was found in the case of S. E. Asia (Table 3). However, it should be considered that in summertime upward air motions over the Caribbean Sea are, on average, about 1/3 weaker than over S. E. Asia (about $-10 \mathrm{mPa} \mathrm{s}^{-1}$ in the Caribbean and about $-32 \mathrm{mPa} \mathrm{s}^{-1}$ over S. E. Asia) and that trends in vertical velocities at $200 \mathrm{mb}$ are very small $\left(+0.4 \mathrm{mPa} \mathrm{s}^{-1}\right.$ per decade).

In any case, the period under study is short for trend analyses and the results should be considered with caution as far as it concerns any anthropogenic effects on tropical cirrus coverage.

\section{SUMMARY AND CONCLUSIONS}

In order to explore the question of whether observed trends in cirrus clouds over Southeast Asia are associated with man-made cirrus contrails or are caused by inter-annual variability, parameters that could possibly control contrail cover in this region such as ambient humidity, temperature and upward motions (Schumann 2000) have been studied as to their inter-annual variability and its relationship with cirrus cloud coverage. For comparison reasons our analysis was also performed for the Caribbean Sea, a region that experiences similar flight frequencies and fuel consumption with S. E. Asia. Over Southeast Asia, there is a small positive trend in cirrus clouds in winter $(+0.1 \%$ cover/decade), which is not statistically significant and is related to small positive trends in deep convective clouds ( $+0.4 \%$ cover/decade). In summer, cirrus clouds are anti-correlated with deep convective clouds over this region and the trends are opposite. In summer, there is a statistically significant decreasing trend in cirrus clouds over S. E. Asia (-4.5\% cover/decade, $99 \%$ confidence level), which is explained by trends in dynamical and thermo-dynamical parameters. Cirrus cloud cover is statistically significant correlated with vertical velocities and air temperature at $200 \mathrm{mb}$ (correlations of -0.7 and -0.6 , 
respectively), explaining the highest part of the observed long-term variability of cirrus clouds over S. E. Asia. The upward air motions are decreasing in summer, leading to a decrease in cirrus cloud amounts. According to our calculations, the vertical velocity related cirrus trend over S. E. Asia in summer is about $-3.5 \%$ cover per decade, indicating that $\sim 78 \%$ of the observed trend in cirrus has been caused by trends in vertical winds. Trends in relative humidity at $200 \mathrm{mb}$ and their correlations with the cirrus trends were not found to be statistically significant in the examined period.

Over the Caribbean Sea, on the other hand, a strong decadal positive trend in cirrus clouds was found in the wintertime $(+2.5 \%$ cover/decade), which is statistically significant correlated to trends in vertical velocities at $200 \mathrm{mb}$ (correlation $-0.8,99 \%$ confidence level). The respective vertical velocity related cirrus trend is about $+2.0 \%$ cover per decade, indicating that $\sim 80 \%$ of the observed trend in cirrus has been caused by trends in vertical winds. The remaining part of cirrus cloud variability in the Caribbean could be related to man-made cirrus contrails, but this part is likely to be small since flight frequencies and fuel consumption in the area are moderate. Therefore, the contribution of regional persistent contrails on the cirrus cloud positive trend in the region is likely to be small. In summertime, trends in cirrus clouds are not significantly correlated to trends in vertical velocities at $200 \mathrm{mb}$ as it was found in the case of S. E. Asia. According to our findings, it is difficult to detect possible effects of regional persistent contrails on cirrus cloud trends over the S. E. Asia air traffic corridors. This is because in winter there are not statistically significant trends in cirrus clouds and in summer trends in dynamics and thermo-dynamics mask this issue. Considering also that flight frequencies and fuel consumption are moderate over the tropical air traffic corridors, it makes it even more difficult to detect and quantify any possible anthropogenic effects.

Acknowledgements This study was conducted within the FP6 Integrated Project "Quantifying the Climate Impact of Global and European Transport Systems" (QUANTIFY, Contract No. 003893-GOCE) and contributes to the ECATS Network of Excellence, both funded by the European Commission. We would like to thank Dr. Klaus Gierens from DLR-IPA for his assistance in the references as well as the unknown reviewers who have greatly helped in improving the study. The study also contributes to the national project PENED (O3ED57) funded by the General Secretariat of Research and Technology. The study also contributes to the national project PENED (O3ED57) funded by the General Secretariat of Research and Technology.

\section{REFERENCES}

Liao, X., W. B. Rossow, and D. Rind, 1995: Comparison between SAGE II and ISCCP highlevel clouds, 1. Global and zonal mean cloud amounts. J. Geophys. Res., 100, 1121-1135.

Mannstein, H., and U. Schumann, 2005: Aircraft induced contrail cirrus over Europe. Meteorol. Z., 14, 549-554.

Minnis, P., J. K. Ayers, R. Palikonda, and D. Phan, 2004: Contrails, cirrus trends, and climate. J. Climate, 17, 1671-1685. 
Rossow, W. B., and R. A. Schiffer, 1999: Advances in understanding clouds from ISCCP. Bull. Amer. Meteor. Soc., 80, 2261-2287.

Sausen, R., K. Gierens, M. Ponater, and U. Schumann, 1998: A diagnostic study of the global distribution of contrails, part I: Present day climate. Theor. Appl. Climatol., 61, 127141.

Sausen, R., I. Isaksen, V. Grewe, D. Hauglustaine, D. S. Lee, G. Myhre, M. O. Köhler, G. Pitari, U. Schumann, F. Stordal, and C. Zerefos, 2005: Aviation radiative forcing in 2000: An update on IPCC (1999). Meteorol. Z., 14, 555-561.

Schumann, U., 2000: Introduction and Review of Previous Assessments: Questions and Previous Answers. In: Schumann, U., and G. T. Amanatidis (Eds.), Aviation, Aerosols, Contrails and Cirrus Clouds $\left(\mathrm{A}^{2} \mathrm{C}^{3}\right)$. Seeheim, Germany, EUR 19428, European Commission, Brussels, 21-26.

Spichtinger, P., 2004: Eisübersättigte Regionen. Ph.D. Thesis, DLR-FB 2004-21, 211 pp. (in German)

Stordal, F., G. Myhre, E. J. G. Stordal, W. B. Rossow, D. S. Lee, D. W. Arlander, and T. Svendby, 2005: Is there a trend in cirrus cloud cover due to aircraft traffic? Atmos. Chem. Phys., 5, 2155-2162.

Stubenrauch, C. J., W. B. Rossow, F. Cheruy, A. Chedin, and N. A. Scott, 1999: Clouds as seen by satellite sounders (3I) and imagers (ISCCP), Part I: Evaluation of cloud parameters. J. Climate, 12, 2189-2213.

Stubenrauch, C. J., and U. Schumann, 2005: Impact of air traffic on cirrus coverage. Geophys. Res. Lett., 32, L14813, doi: 10.1029/2005GL022707.

Wang, P. H., P. Minnis, M. P. McCormick, G. S. Kent, and K. M. Skeens, 1996: A 6-year climatology of cloud occurrence frequency from Stratospheric Aerosol and Gas Experiment II observations (1985 - 1990). J. Geophys. Res., 101, 29407-29429.

Wang, P. H., P. Minnis, B. A. Wielicki, T. Wong, R. D. Cess, M. Zhang, L. B. Vann, and G. S. Kent, 2003: Characteristics of the 1997/1998 El Nino cloud distributions from SAGE II observations. J. Geophys. Res., 108, AAC5.1-AAC5.11, doi:10.1029/2002JD002501.

Zerefos, C. S., K. Eleftheratos, D. S. Balis, P. Zanis, G. Tselioudis, and C. Meleti, 2003: Evidence of impact of aviation on cirrus cloud formation. Atmos. Chem. Phys., 3, 16331644.

Zerefos, C. S., K. Eleftheratos, P. Zanis, D. S. Balis, and G. Tselioudis, 2007: Search for manmade cirrus contrails over Southeast Asia. Terr. Atmos. Ocean. Sci., 18, 459-474, doi: 10.3319/TAO.2007.18.3.459(EA). 